ARTICLE

https://doi.org/10.1038/s41467-019-09765-y

\title{
Single platinum atoms embedded in nanoporous cobalt selenide as electrocatalyst for accelerating hydrogen evolution reaction
}

\author{
Kang Jiang ${ }^{1,7}$, Boyang Liü ${ }^{2,7}$, Min Luo ${ }^{3,7}$, Shoucong Ning (i) ${ }^{4}$, Ming Peng ${ }^{1}$, Yang Zhao ${ }^{1}$, Ying-Rui Lu ${ }^{5}$,
} Ting-Shan Chan ${ }^{5}$, Frank M.F. de Groot ${ }^{6}$ \& Yongwen Tan (1) ${ }^{1}$

Designing efficient electrocatalysts for hydrogen evolution reaction is significant for renewable and sustainable energy conversion. Here, we report single-atom platinum decorated nanoporous $\mathrm{Co}_{0.85} \mathrm{Se}\left(\mathrm{Pt} / \mathrm{np}-\mathrm{Co}_{0.85} \mathrm{Se}\right)$ as efficient electrocatalysts for hydrogen evolution. The achieved $\mathrm{Pt} / \mathrm{np}-\mathrm{Co}_{0.85} \mathrm{Se}$ shows high catalytic performance with a near-zero onset overpotential, a low Tafel slope of $35 \mathrm{mV} \mathrm{dec}^{-1}$, and a high turnover frequency of $3.93 \mathrm{~s}^{-1}$ at $-100 \mathrm{mV}$ in neutral media, outperforming commercial Pt/C catalyst and other reported transition-metal-based compounds. Operando $\mathrm{X}$-ray absorption spectroscopy studies combined with density functional theory calculations indicate that single-atom platinum in $\mathrm{Pt} / \mathrm{np}$ $\mathrm{Co}_{0.85} \mathrm{Se}$ not only can optimize surface states of $\mathrm{Co}_{0.85} \mathrm{Se}$ active centers under realistic working conditions, but also can significantly reduce energy barriers of water dissociation and improve adsorption/desorption behavior of hydrogen, which synergistically promote thermodynamics and kinetics. This work opens up further opportunities for local electronic structures tuning of electrocatalysts to effectively manipulate its catalytic properties by an atomic-level engineering strategy.

\footnotetext{
${ }^{1}$ College of Materials Science and Engineering, Hunan University, 410082 Changsha, Hunan, China. ${ }^{2}$ Department of Physics, AlbaNova University Center, Stockholm University, SE-10691 Stockholm, Sweden. ${ }^{3}$ Department of Physics, Shanghai Polytechnic University, 201209 Shanghai, China. ${ }^{4}$ Department of Materials Science and Engineering, National University of Singapore, 9 Engineering Drive 1, Singapore 117575, Singapore. ${ }^{5}$ National Synchrotron Radiation Research Center, Hsinchu 300, Taiwan. ${ }^{6}$ Inorganic Chemistry \& Catalysis, Debye Institute for Nanomaterials Science, Utrecht University, Universiteitsweg 99, 3584 CG Utrecht, The Netherlands. ${ }^{7}$ These authors contributed equally: Kang Jiang, Boyang Liu, Min Luo. Correspondence and requests for materials should be addressed to Y.T. (email: tanyw@hnu.edu.cn)
} 
E lectrocatalytic water splitting to generate hydrogen is widely regarded as an efficient and prospective sustainable energy technology ${ }^{1}$. Furthermore, electrochemically generated $\mathrm{H}_{2}$ may be used as feedstock in industrially relevant reactions like Fischer-Tropsch and Haber-Bosch, which are currently dependent on fossil-fuel derived $\mathrm{H}_{2}$ (i.e., derived from steam reforming of natural gas). Highly efficient catalysts with low overpotential and fast kinetics in the hydrogen evolution reaction (HER) are critical toward large-scale hydrogen production. Pt is generally considered as the most active catalyst for HER, but their scarcity and high cost greatly hamper its large-scale applications ${ }^{2}$. For cost-efficiency, numerous non-precious materials have been found to have excellent HER catalytic performance, including metal oxides or hydroxides ${ }^{3-5}$, metal nitrides ${ }^{6}$, metal chalcogenides $^{7-16}$, and metal phosphides ${ }^{17-23}$. Among them, the nonstoichiometric cobalt selenides $\left(\mathrm{Co}_{0.85} \mathrm{Se}\right)$ are one type of promising catalysts for HER applications ${ }^{24-27}$. However, everreported catalysts based on non-noble metal suffer from sluggish catalytic kinetics and poor stability, thus calling for further exploitation of highly efficient HER catalysts through material structure innovation.

Recently, many researches have suggested that supported Pt nanostructures are typically used to promote catalytic activity by advantageous local catalyst-Pt interfacial interactions ${ }^{3-5,9}$. Given the noble nature of $\mathrm{Pt}$, reducing the nanostructures to atomically distributed Pt centers supported on catalysts could significantly decrease Pt usages and maximize atom efficiency ${ }^{28,29}$. In particular, significant progresses have been made on the constructing of atomic-scale Pt on various supports, such as metal ${ }^{30}$, metal oxides $^{31}$, metal phosphides ${ }^{32}$, two-dimensional $\mathrm{MoS}_{2}{ }^{11,14}$, carbon nanotubes ${ }^{33}$, graphene ${ }^{28,34}, \mathrm{MXene}^{35}$, etc. Some of these works have demonstrated that the single metal atoms modified catalysts are significantly higher catalytic activity than non-modified ones towards HER due to strong metal-support interactions (SMSI) ${ }^{31,36}$. However, at present, direct insights into how single-atom metal is beneficial to promote HER activity of current catalysts are rarely available under realistic reaction conditions, especially for cobalt selenides. So from feasible and representative perspectives, developing single Pt atoms modified cobalt selenides catalyst is key to fundamentally understanding the synergistic effect of single Pt atoms and cobalt selenides that accounts for HER enhancement.

Herein, we construct single-atom Pt supported on nanoporous cobalt selenide (denoted as $\mathrm{Pt} / \mathrm{np}-\mathrm{Co}_{0.85} \mathrm{Se}$ ) catalyst as a model to assess the HER activity and understand the activity origins at atomic-level. The $\mathrm{Pt} / \mathrm{np}-\mathrm{Co}_{0.85} \mathrm{Se}$ catalyst with an ultralow singleatom Pt loading while possess a near-zero onset overpotential, a low Tafel slope, and a high turnover frequency (TOF), outperforming commercial $\mathrm{Pt} / \mathrm{C}$ catalyst and other reported transition-metal-based compounds in neutral electrolyte. Operando X-ray absorption spectroscopy (XAS) studies combined with density functional theory (DFT) calculations reveal that single $\mathrm{Pt}$ atoms strongly induce the charge redistribution at the interface region of $\mathrm{Pt} / \mathrm{np}-\mathrm{Co}_{0.85} \mathrm{Se}$ and significantly promote water dissociation process, while improve adsorption/desorption behavior of $\mathrm{H}$, further facilitating the HER kinetics. Thus, the synergy between atomic-level $\mathrm{Pt}$ and $\mathrm{np}-\mathrm{Co}_{0.85} \mathrm{Se}$ is mainly responsible for excellent catalytic activity of $\mathrm{Pt} / \mathrm{np}-\mathrm{Co}_{0.85} \mathrm{Se}$ in HER processes. The superior catalytic performance of the $\mathrm{Pt} / \mathrm{np}$ $\mathrm{Co}_{0.85}$ Se catalyst highlights the importance of atomic-level engineering strategy for electronic structure tuning of electrocatalysts to effectively manipulate theirs catalytic properties.

\section{Results}

Material synthesis and characterization. The $\mathrm{np}-\mathrm{Co}_{0.85} \mathrm{Se}$ catalyst was prepared by an electrochemically selective etching

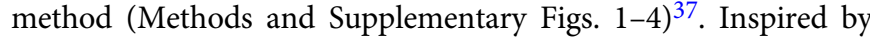
the potential cycling method of depositing Pt atom on working electrode ${ }^{32,33}$, electrochemical vacancy manufacturing and $\mathrm{Pt}$ atom embedding were conducted by cyclic voltammetry $(\mathrm{CV})$ using Pt foil as counter electrode in a three-electrode cell containing $0.5 \mathrm{M} \mathrm{H}_{2} \mathrm{SO}_{4}$ (Fig. 1a, Methods). During the cyclic process, slight $\mathrm{Co}$ atoms dissolved from the $\mathrm{np}-\mathrm{Co}_{0.85} \mathrm{Se}$ to form Co vacancies, thus providing anchor sites for the embedding of $\mathrm{Pt}$ atoms and improving the HER performance (Supplementary Note 1 and Supplementary Figs. 5 and 6) ${ }^{38,39}$. The bicontinuous nanoporous structure with a high surface area facilitates Pt ions' diffusing into $\mathrm{Co}$ vacancies of nano-sized $\mathrm{Co}_{0.85} \mathrm{Se}$ ligaments, forming the homogeneous single-atom Pt doped $\mathrm{np}-\mathrm{Co}_{0.85} \mathrm{Se}$ (Supplementary Fig. 7). CV measurements under non-catalytic conditions were used to detect the feature voltammetric response of $\mathrm{Pt}^{40}$. Regions of interest include the $\mathrm{Pt}-\mathrm{H}$ adsorption/desorption peaks and Pt-O formation/reduction peaks. However, these characteristic peaks of Pt cannot be observed on Pt/np$\mathrm{Co}_{0.85} \mathrm{Se}$, indicative of ultralow Pt loading (Supplementary Fig. 8) ${ }^{33}$. X-ray diffraction (XRD) pattern of $\mathrm{Pt} / \mathrm{np}-\mathrm{Co}_{0.85} \mathrm{Se}$ displays a similar crystal structure with that of hexagonal $\mathrm{Co}_{0.85} \mathrm{Se}$ (JPCDS card no. 52-1008) excepting for a slight shift (Fig. 1b and Supplementary Fig. 9), indicating that the atomic-level Pt dopant did not form crystalline segregated bi-phases, but was wellincorporated into the $\mathrm{Co}_{0.85} \mathrm{Se}$ crystal lattice. Scanning electron microscope (SEM) (Fig. 1c) and transmission electron microscopy (TEM) (Supplementary Fig. 10) characterizations confirmed that $\mathrm{Pt} / \mathrm{np}-\mathrm{Co}_{0.85} \mathrm{Se}$ remains the porous morphology of $\mathrm{np}-\mathrm{Co}_{0.85} \mathrm{Se}$ precursor after surface doping, and no Pt nanoparticles are observed from the surface of np- $\mathrm{Co}_{0.85} \mathrm{Se}$. High-angle annular dark-field scanning TEM (HAADF-STEM) measurements were adopted to directly observe the presence of Pt on the

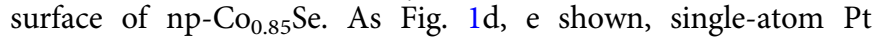
appearing as bright spots can be found to be well dispersed in the lattice of $\mathrm{Co}_{0.85} \mathrm{Se}$, confirming the formation of single-atom dispersed catalyst. Similarly, the loosely interatomic distances and the different intensity of line profiles also indicate the isolated $\mathrm{Pt}$ atoms (Fig. 1f). The energy-dispersive X-ray (EDX) spectroscopy elemental analysis further demonstrate the homogenous distribution of $\mathrm{Co}, \mathrm{Se}$, and $\mathrm{Pt}$ throughout the ligaments surface in Pt/ np- $\mathrm{Co}_{0.85} \mathrm{Se}$ (Fig. $1 \mathrm{~g}$ ), conforming the uniform dispersion of single-atom Pt on $\mathrm{np}-\mathrm{Co}_{0.85} \mathrm{Se}$. $\sim 1.03 \mathrm{wt} \% \mathrm{Pt}$ loading was determined for the $\mathrm{Pt} / \mathrm{np}-\mathrm{Co}_{0.85} \mathrm{Se}$ catalyst, as ascertained by inductively coupled plasma optical emission spectrometry (ICP-OES) results. By tuning the CV cycles (Supplementary Fig. 5), lower mass loading catalyst with nonuniform distribution of single $\mathrm{Pt}$ atoms (denoted as $\mathrm{Pt}_{\mathrm{S}} / \mathrm{np}-\mathrm{Co}_{0.85} \mathrm{Se}, 3000 \mathrm{CV}$ cycles) and higher mass loading catalyst with $\mathrm{Pt}$ nanoparticles (denoted as $\mathrm{Pt}_{\mathrm{N}} / \mathrm{np}$ $\mathrm{Co}_{0.85} \mathrm{Se}, 6000 \mathrm{CV}$ cycles) were synthesized. This variation in size from single atoms, nanoclusters to nanoparticles is verified by HAADF-STEM measurements (Supplementary Fig. 11).

X-ray photoelectron spectroscopy (XPS) was performed to investigate the chemical composition and binding status of the catalysts. Figure 2a shows the Pt $4 \mathrm{f}$ core level spectra of $\mathrm{Pt} / \mathrm{C}$ and $\mathrm{Pt} / \mathrm{np}-\mathrm{Co}_{0.85} \mathrm{Se}$. Pt $4 \mathrm{f}_{7 / 2}$ and $4 \mathrm{f}_{5 / 2}$ orbitals of the $\mathrm{Pt} / \mathrm{C}$ are observed at binding energies of $71.2 \mathrm{eV}$ and $74.5 \mathrm{eV}$, respectively, indicative of $\mathrm{Pt}^{032}$. However, the two $\mathrm{Pt} 4 \mathrm{f}$ orbitals of the $\mathrm{Pt} / \mathrm{np}-\mathrm{Co}_{0.85} \mathrm{Se}$ are located at $71.8 \mathrm{eV}$ and $75.1 \mathrm{eV}$, which confirm Pt atoms with partially positive charge $\left(\mathrm{Pt}^{\delta+}\right)$ owing to the electronic interaction between single $\mathrm{Pt}$ atoms and $\mathrm{np}-\mathrm{Co}_{0.85} \mathrm{Se}^{41,42}$. In the Co $2 \mathrm{p}$ region, enhanced oxidation degree of the surface Co cations after atomic-level Pt doping causes a positive energy shift in Co XPS (Supplementary Fig. 12a). The fitted ratios of $\mathrm{Co}^{3+}$ to $\mathrm{Co}^{2+}$ of Pt/ $n p-\mathrm{Co}_{0.85} \mathrm{Se}(2.27)$ are higher than that of pristine $\mathrm{np}-\mathrm{Co}_{0.85} \mathrm{Se}$ (1.02), implying the more $\mathrm{Co}^{2+}$ vacancies formed during $\mathrm{Pt}$ doping according to the charge neutrality ${ }^{43}$. In the Se $3 \mathrm{~d}$ spectra, 
a
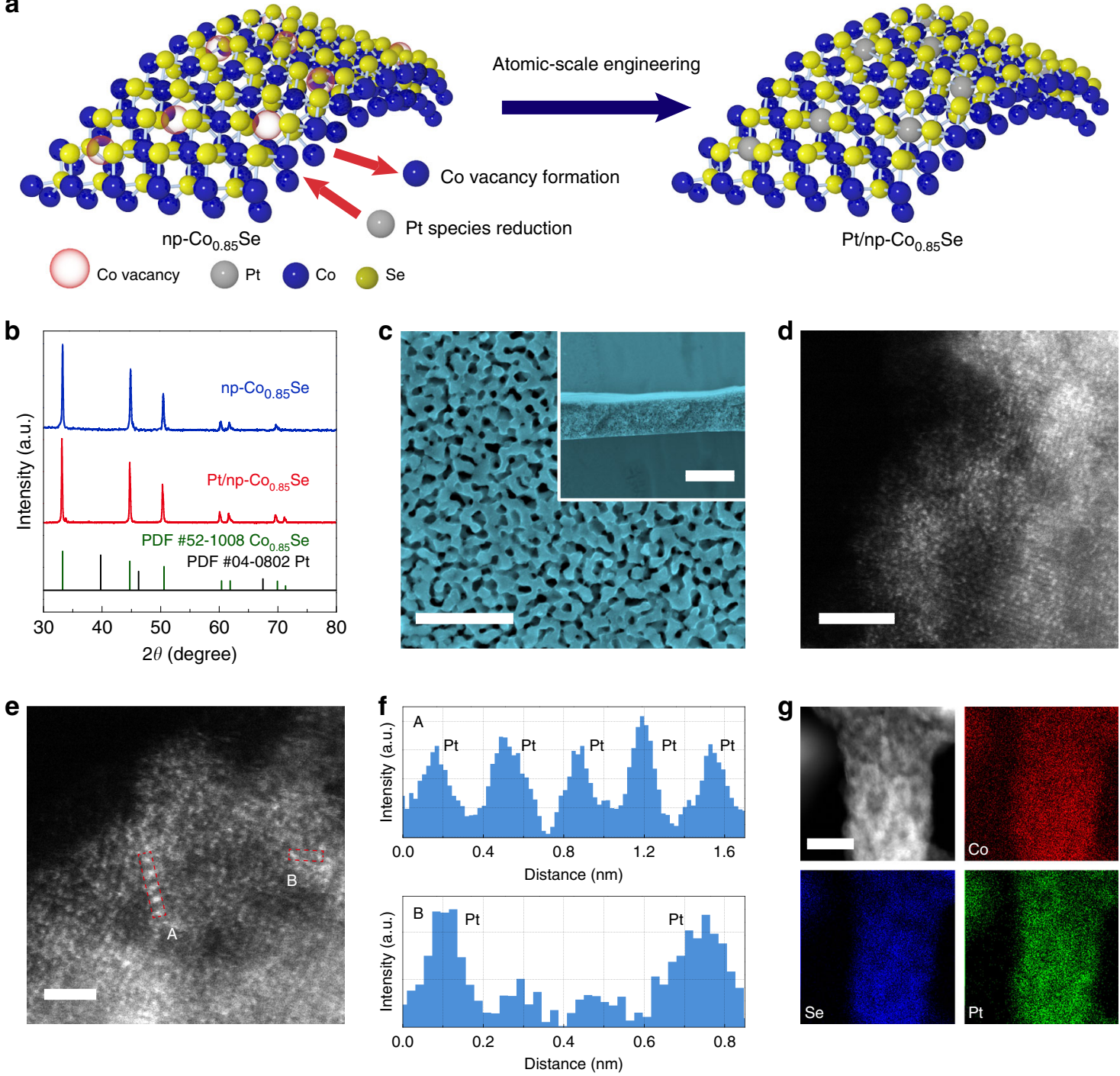

Fig. 1 Fabrication and structural characterization of $\mathrm{Pt} / \mathrm{np}-\mathrm{Co}_{0.85} \mathrm{Se}$. a Schematic illustration of the fabrication procedure. $\mathbf{b} \mathrm{X}$-ray diffraction (XRD) patterns

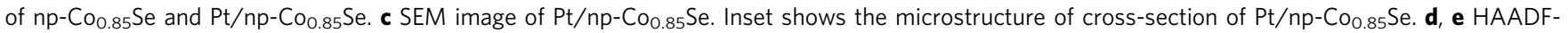
STEM images of $\mathrm{Pt} / \mathrm{np}-\mathrm{CO}_{0.85} \mathrm{Se}$. $\mathbf{f}$ Line-scanning intensity profile obtained from the area highlighted with red rectangles in regions $\mathrm{A}$ and $\mathrm{B}$ in $\mathbf{e}$. $\mathbf{g}$ The STEM-EDX elemental mapping of Pt/np-Co ${ }_{0.85}$ Se. Scale bars: c $500 \mathrm{~nm}$, inset: $20 \mu \mathrm{m}$. d $2 \mathrm{~nm}$. e $1 \mathrm{~nm} . \mathbf{g} 10 \mathrm{~nm}$

the peaks of Se $3 \mathrm{~d}$ for $\mathrm{Pt} / \mathrm{np}-\mathrm{Co}_{0.85} \mathrm{Se}$ show a positive energy shift compared to that of $\mathrm{np}-\mathrm{Co}_{0.85} \mathrm{Se}$, which is ascribed to the doping of $\mathrm{Pt}$ in lattice resulting in the increased electron density (Supplementary Fig. 12b) ${ }^{44}$.

$\mathrm{X}$-ray absorption spectroscopy (XAS) was used to investigate the electronic and local structure of catalysts ${ }^{45}$. Figure $2 \mathrm{~b}, \mathrm{c}$ exhibit $\mathrm{Pt}_{3}$-edge $\mathrm{X}$-ray absorption near-edge structure (XANES) (Fig. 2b) and Fourier transform extended X-ray absorption fine structure (FT-EXAFS) (Fig. 2c) spectra, together with the Pt foil, commercial $\mathrm{Pt} / \mathrm{C}, \mathrm{PtO}_{2}$ as a comparison. The XANES spectra show that the white-line intensity of $\mathrm{Pt} / \mathrm{np}-\mathrm{Co}_{0.85} \mathrm{Se}$ is obviously higher than that of $\mathrm{Pt}$ foil and commercial $\mathrm{Pt} / \mathrm{C}$, confirming the positive valence state $(0.8$, inset of Fig. $2 \mathrm{~b})$ of $\mathrm{Pt}$ atoms, which could be attributed to the electron transfer from $\mathrm{Pt}$ to $\mathrm{Se}$ in $\mathrm{Pt}-\mathrm{Se}$ bonds of $\mathrm{Pt} / \mathrm{np}-\mathrm{Co}_{0.85} \mathrm{Se}^{14}$. FT-EXAFS spectra in Fig. $2 \mathrm{c}$ show a conspicuous peak at $2.03 \AA$ from the Pt-Se contribution, indicating the single-atom nature of $\mathrm{Pt}$ in $\mathrm{Pt} / \mathrm{np}-\mathrm{Co}_{0.85} \mathrm{Se}$. Figure 2d, e exhibit the Se K-edge XANES and FT-EXAFS spectra of $\mathrm{np}-\mathrm{Co}_{0.85} \mathrm{Se}$ and $\mathrm{Pt} / \mathrm{np}-\mathrm{Co}_{0.85} \mathrm{Se}$, respectively. The FTEXAFS spectrum (Fig. 2e) of np- $\mathrm{Co}_{0.85} \mathrm{Se}$ exhibits a coordination peaks of Se-Co at $2.09 \AA, \sim 0.06 \AA$ longer than that of Se-Pt, which suggests the equal radial distance of $\mathrm{Se}-\mathrm{Co}$ and $\mathrm{Se}-\mathrm{Pt}$ shell ${ }^{16}$. Moreover, the enhanced intensity of Se-Co $(\mathrm{Se}-\mathrm{Pt})$ shell in the FT-EXAFS signals indicates that $\mathrm{Pt}$ atoms occupy Co vacancies in the lattice of $\mathrm{np}-\mathrm{Co}_{0.85} \mathrm{Se}$, resulting in more the coordination number of Se atoms. The Co K-edge XANES spectra of $\mathrm{np}$ $\mathrm{Co}_{0.85} \mathrm{Se}$ and $\mathrm{Pt} / \mathrm{np}-\mathrm{Co}_{0.85} \mathrm{Se}$ show similar but slightly different adsorption features (Fig. 2f). The higher intensity white-line of $\mathrm{Pt} / \mathrm{np}-\mathrm{Co}_{0.85} \mathrm{Se}$ compared to $\mathrm{np}-\mathrm{Co}_{0.85} \mathrm{Se}$ implies the local atomic arrangement of Co atom caused by single-atom Pt doping. This phenomenon is further definitely verified by the FT-EXAFS spectra (Fig. 2g). A prominent peak is observed at $2.09 \AA$, corroborating the Co-Se scattering contribution. The peak intensity decreases after the introduction of the single-atom $\mathrm{Pt}$ in $\mathrm{np}-\mathrm{Co}_{0.85} \mathrm{Se}$, which might originate from the formation of Se vacancies for the partial rearrangement of Co atoms ${ }^{11}$. More importantly, the peak from the Co-Se contribution shifts to a higher value by $0.04 \AA$ compared to that of $\mathrm{np}-\mathrm{Co}_{0.85} \mathrm{Se}$, which may originate from the structural lattice distortion caused by the substitutional doping of Pt. 


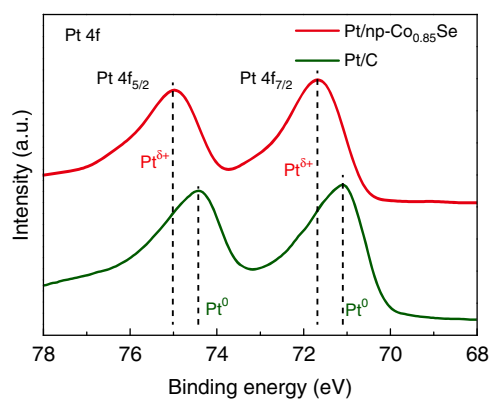

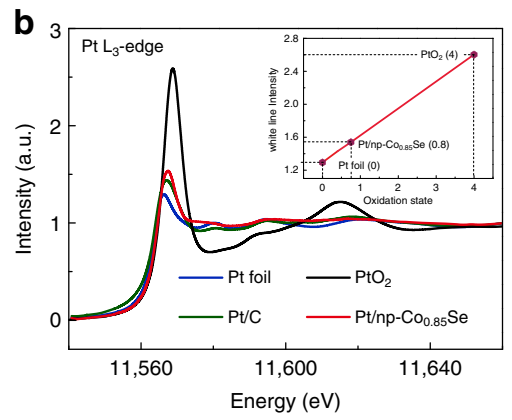

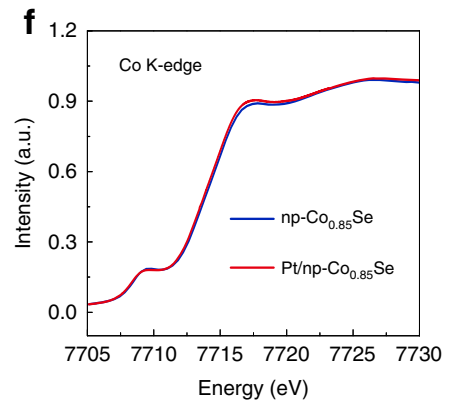

Energy $(\mathrm{eV})$
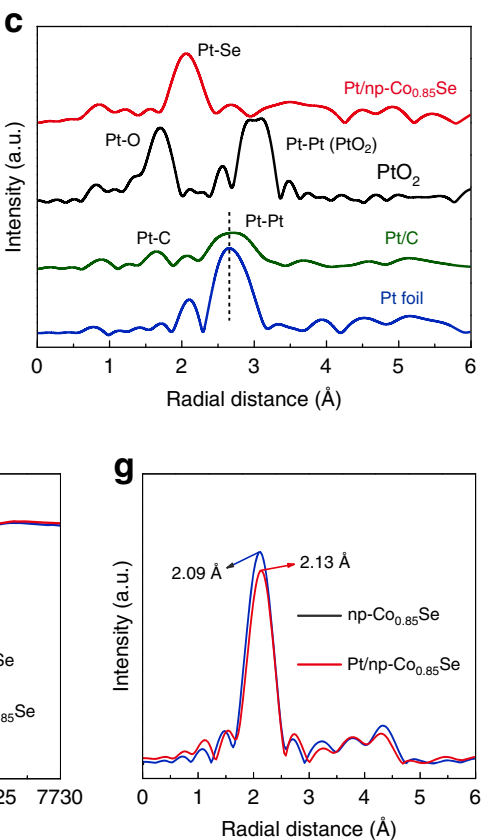
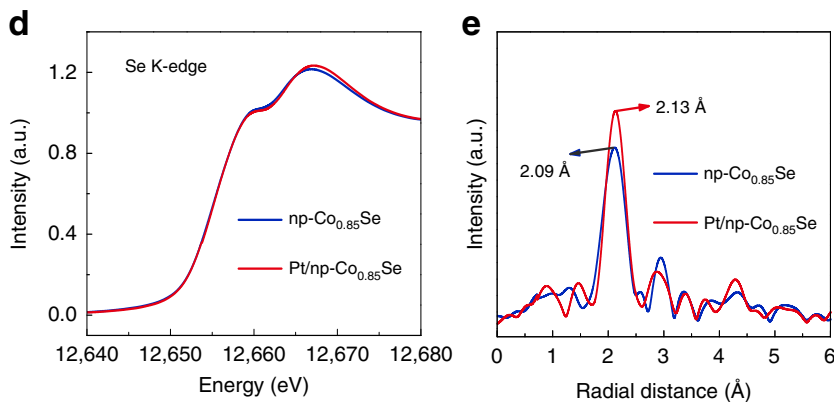

Fig. 2 X-ray photoelectron spectroscopy (XPS) and X-ray absorption spectroscopy (XAS) characterizations. a XPS spectra of Pt/np-Co ${ }_{0.85} \mathrm{Se}_{\mathrm{s}}$ and commercial $\mathrm{Pt} / \mathrm{C}$ in $\mathrm{Pt} 4 \mathrm{f}$ regions. $\mathbf{b}$ The normalized XANES at the $\mathrm{Pt} \mathrm{L}_{3}$-edge of $\mathrm{Pt}$ foil, commercial Pt/C, $\mathrm{PtO}{ }_{2}$, and $\mathrm{Pt} / \mathrm{np}-\mathrm{Co}_{0.85} \mathrm{Se}$. The inset shows the average oxidation state of $\mathrm{Pt}$ in $\mathrm{Pt} / \mathrm{np}-\mathrm{CO}_{0.85} \mathrm{Se}$. c Corresponding FT-EXAFS spectra from $\mathbf{b}$. d The normalized XANES spectra at the Se K-edge of np$\mathrm{Co}_{0.85} \mathrm{Se}$ and $\mathrm{Pt} / \mathrm{np}-\mathrm{Co}_{0.85} \mathrm{Se}$. e Corresponding FT-EXAFS spectra from d. $\mathbf{f}$ The normalized XANES spectra at the $\mathrm{Co} \mathrm{K}$-edge of $\mathrm{np}-\mathrm{Co}_{0.85} \mathrm{Se}$ and $\mathrm{Pt} / \mathrm{np}$ $\mathrm{Co}_{0.85} \mathrm{Se}$. $\mathbf{g}$ Corresponding FT-EXAFS spectra from $\mathbf{f}$

Electrochemical analysis. The HER activities of $\mathrm{Pt} / \mathrm{np}-\mathrm{Co}_{0.85} \mathrm{Se}$ was evaluated in a three-electrode system containing $1.0 \mathrm{M}$ phosphate buffer solutions ( $\mathrm{PBS}, \mathrm{pH}=7.0$ ). Figure $3 \mathrm{a}$ exhibits the polarization curves of $\mathrm{np}-\mathrm{Co}_{0.85} \mathrm{Se}$ and $\mathrm{Pt} / \mathrm{np}-\mathrm{Co}_{0.85} \mathrm{Se}$, together with a commercial $\mathrm{Pt} / \mathrm{C}$ as the benchmark. Although comparable HER activity at low applied potentials, $\mathrm{Pt} / \mathrm{np}$ $\mathrm{Co}_{0.85}$ Se can far surpass commercial $\mathrm{Pt} / \mathrm{C}$ at high overpotentials ( greater than $-19 \mathrm{mV}$ ), presumably owing to its bicontinuous nanoporous structure that enables better mass-transfer process. The potential required to reach an HER current density $(j)$ of $-10 \mathrm{~mA} \mathrm{~cm}^{-2}$ is a key HER performance metric. Only $-55 \mathrm{mV}$ vs. reversible hydrogen electrode (RHE) overpotential was required for $\mathrm{Pt} / \mathrm{np}-\mathrm{Co}_{0.85} \mathrm{Se}$ to reach $10 \mathrm{~mA} \mathrm{~cm}^{-2}$. In comparison, the $\mathrm{np}-\mathrm{Co}_{0.85} \mathrm{Se}$ requests the overpotential of $-264 \mathrm{mV}$ for $j=-10 \mathrm{~mA} \mathrm{~cm}{ }^{-2}$ electrode current. The tafel slope presented in Fig. $3 \mathrm{~b}$ gives a small Tafel slope of $35 \mathrm{mV}$ per decade $\left(\mathrm{mV} \mathrm{dec}^{-1}\right)$ for $\mathrm{Pt} / \mathrm{np}-\mathrm{Co}_{0.85} \mathrm{Se}$, lower than that of $\mathrm{Pt} / \mathrm{C}\left(37 \mathrm{mV} \mathrm{dec}^{-1}\right)$ and $\mathrm{np}-\mathrm{Co}_{0.85} \mathrm{Se}\left(90 \mathrm{mV} \mathrm{dec}{ }^{-1}\right)$, revealing fast HER kinetics derived from the advantage of introducing $\mathrm{Pt}$ single atoms. Additionally, the $\mathrm{Pt} / \mathrm{np}-\mathrm{Co}_{0.85}$ Se electrode shows the onset potential (potential required to reach $-1 \mathrm{~mA} \mathrm{~cm}^{-2}$ ) for $\mathrm{H}_{2}$ evolution at $-12 \mathrm{mV}$ (Fig. 3c), which can only be observed for commercial Pt/C catalyst. Whereas the onset potential is shifted substantially negative for $\mathrm{np}-\mathrm{Co}_{0.85} \mathrm{Se}$ catalyst. Furthermore, the mass activity of HER for $\mathrm{Pt} / \mathrm{np}-\mathrm{Co}_{0.85} \mathrm{Se}$ at an overpotential of $-100 \mathrm{mV}$ is $1.32 \mathrm{~A} \mathrm{mg}^{-1}$ by normalizing to the Pt loading, which is 11 times greater than that of the commercial HER catalyst $(10 \mathrm{wt} \% \mathrm{Pt} / \mathrm{C}$, $0.12 \mathrm{~A} \mathrm{mg}^{-1}$ ) (Fig. 3d and Supplementary Note 2) and also higher than that of Pt-based catalysts reported recently (Supplementary Table 1$)^{32,46}$. This result indicates that single-atom $\mathrm{Pt}$ anchored on the $\mathrm{np}-\mathrm{Co}_{0.85} \mathrm{Se}$ can maximize the catalytic activity, decreasing the cost of HER catalysts. The above merits of the $\mathrm{Pt} / \mathrm{np}-\mathrm{Co}_{0.85} \mathrm{Se}$, including low overpotential and Tafel slope, are superior to commercial $\mathrm{Pt} / \mathrm{C}$ and most previously reported catalysts in the neutral solution (Fig. $3 \mathrm{e}$ and
Supplementary Table 2) $)^{12,19,21,22,47}$. The TOF of $\mathrm{Pt} / \mathrm{np}-\mathrm{Co}_{0.85} \mathrm{Se}$ at $-100 \mathrm{mV}$ vs. RHE were calculated to be $3.93 \mathrm{~s}^{-1}$ (Fig. $3 \mathrm{f}$ and Supplementary Note 3 ), which is better than that of np$\mathrm{Co}_{0.85} \mathrm{Se}\left(0.17 \mathrm{~s}^{-1}\right)$ and most reported catalysts (Supplementary Table 3$)^{23,48-51}$. Afterwards, gas chromatography was introduced to analyze the $\mathrm{H}_{2}$ production, which shows that the Faraday efficiency of $\mathrm{Pt} / \mathrm{np}-\mathrm{Co}_{0.85} \mathrm{Se}$ is close to $100 \%$ under different applied potentials (Fig. $3 \mathrm{~g}, \mathrm{~h}$ ).

Electrochemical impedance spectroscopy (EIS) analysis further evidences that the introduction of atomic-level $\mathrm{Pt}$ in $\mathrm{np}-\mathrm{Co}_{0.85} \mathrm{Se}$ generates low internal resistance and rapid charge transfer behavior for a low onset potential and fast HER kinetics (Supplementary Fig. 13). Further, double-layer capacitance $\left(C_{\mathrm{dl}}\right)$, which was used as indicator of the effective electrochemically active surface area, was examined for studied catalysts. Our results reveal a considerably larger $C_{\mathrm{dl}}$ of $\mathrm{Pt} / \mathrm{np}-\mathrm{Co}_{0.85} \mathrm{Se}(57.2 \mathrm{mF}$ $\mathrm{cm}^{-2}$ ) compared with $\mathrm{np}-\mathrm{Co}_{0.85} \mathrm{Se}\left(34.1 \mathrm{mF} \mathrm{cm}^{-2}\right)$, implying more accessible active sites constructed on $\mathrm{Pt} / \mathrm{np}-\mathrm{Co}_{0.85} \mathrm{Se}$ catalyst (Supplementary Fig. 14). Beside activity, we performed an accelerated cyclic voltammetry cycling test to evidence this catalytic robustness with negligible shift of polarization curves after 3000 cycles (Fig. 3i). A long-term stability testing on Pt/np$\mathrm{Co}_{0.85} \mathrm{Se}$ catalyst by means of chronoamperometry $(\mathrm{j} \sim \mathrm{t})$, showing negligible current decay over $40 \mathrm{~h}$ at a constant voltage operation (Fig. 3j). The SEM characterizations of the $\mathrm{Pt} / \mathrm{np}$ $\mathrm{Co}_{0.85} \mathrm{Se}$ electrode also confirm that detectable morphology changes cannot be seen after long-term HER operation (Supplementary Fig. 15a, b). The HAADF-STEM images (Supplementary Fig. 15c, d) and XAS results (Supplementary Fig. 16) confirmed that the single-atom Pt remained after the long-term HER operation, which indicate that the single-atom Pt possesses excellent stability. In addition to neutral electrolyte, $\mathrm{Pt} /$ np- $\mathrm{Co}_{0.85}$ Se also has high activity and stability toward HER in acidic and basic electrolytes (Supplementary Figs. 17-18 and Supplementary Table 1). 

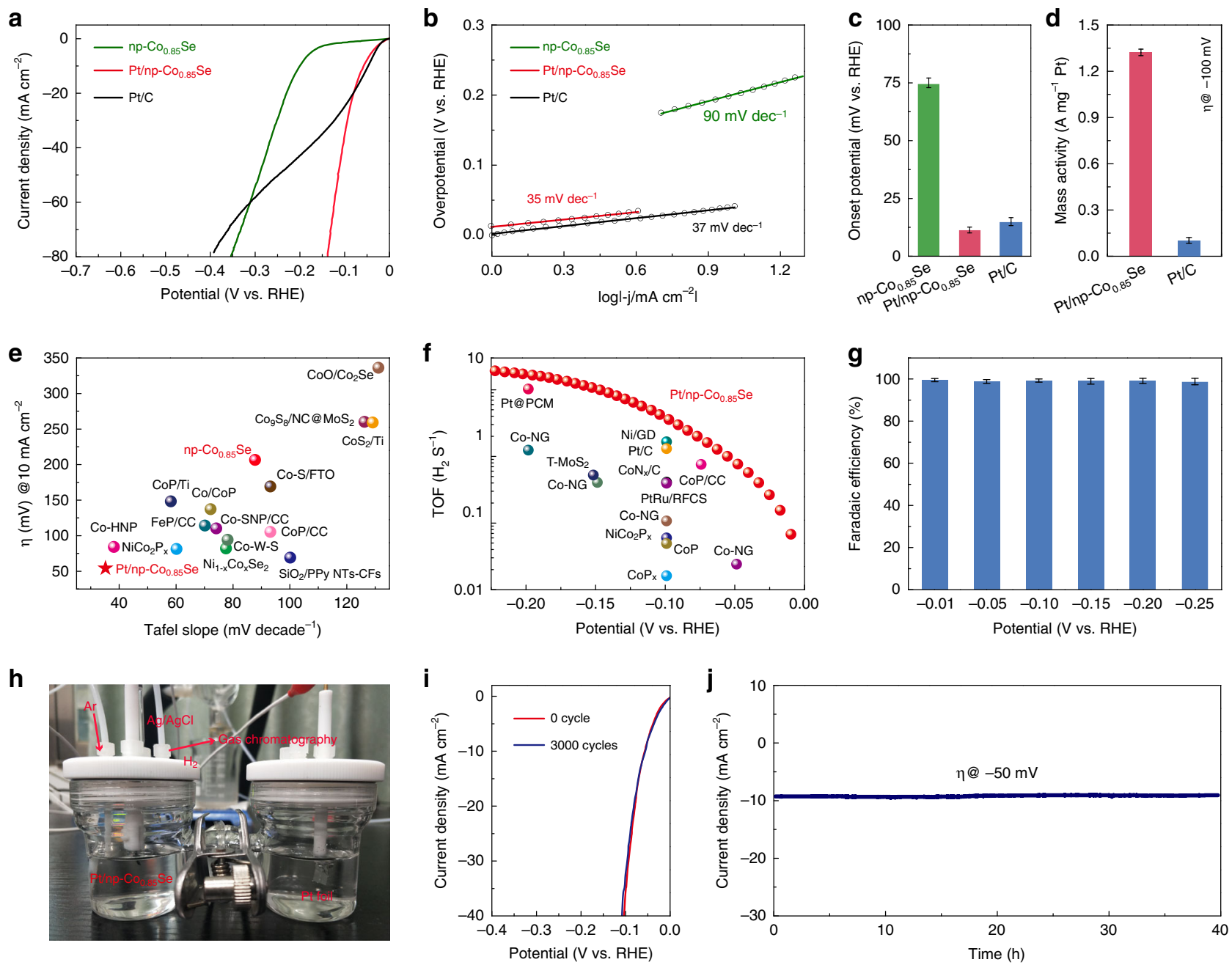

Fig. 3 Electrochemical hydrogen evolution reaction (HER) performance. a HER polarization curves of np- $\mathrm{Co}_{0.85} \mathrm{Se}_{1} \mathrm{Pt} / \mathrm{np}-\mathrm{Co}_{0.85} \mathrm{Se}$ and $\mathrm{Pt} / \mathrm{C}$. $\mathbf{b}$ Corresponding to Tafel plots of the presented data in $\mathbf{a}$. $\mathbf{c}$ Corresponding to onset potential at $-1 \mathrm{~mA} \mathrm{~cm} \mathrm{~cm}^{-2}$ of the presented data in $\mathbf{a}$. $\mathbf{d}$ The mass activity of $\mathrm{Pt} / \mathrm{np}-\mathrm{Co}_{0.85} \mathrm{Se}$ and state-of-the-art Pt/C. e Comparison of merit with respect to both kinetics (Tafel slope) and activity (the overpotential required to achieve $-10 \mathrm{~mA} \mathrm{~cm}^{-2}$ ), with references all measured in neutral medium. $\mathbf{f}$ TOF values of $\mathrm{Pt} / \mathrm{np}-\mathrm{Co}_{0.85} \mathrm{Se}$ (red dot), together with previous reported HER electrocatalysts at $-100 \mathrm{mV}$ vs. RHE. $\mathbf{g}$ Faradaic efficiency of $\mathrm{Pt} / \mathrm{np}-\mathrm{Co}_{0.85} \mathrm{Se}$ at different applied potentials. $\mathbf{h}$ The detail of hydrogen Faradaic efficiency measurement. i Accelerated HER polarization curves of $\mathrm{Pt} / \mathrm{np}-\mathrm{Co}_{0.85} \mathrm{Se}$. $\mathbf{j}$ Current density vs. time ( $i-t$ ) curves of $\mathrm{Pt} / \mathrm{np}-\mathrm{Co}_{0.85} \mathrm{Se}$ recorded for $40 \mathrm{~h} \mathrm{~s}$ at $-50 \mathrm{mV}$ vs. RHE

HER enhancement mechanism. To gain insights on the origins of the high activities of $\mathrm{Pt} / \mathrm{np}-\mathrm{Co}_{0.85} \mathrm{Se}$ in the neutral electrolyte, The in situ and operando Co K-edge XANES and FT-EXAFS spectra were measured under HER working conditions to probe the electronic structure and local atomic environment changes of $\mathrm{np}-\mathrm{Co}_{0.85} \mathrm{Se}$ and $\mathrm{Pt} / \mathrm{np}-\mathrm{Co}_{0.85} \mathrm{Se}$ with a homemade operando cell (Supplementary Note 4 and Fig. 19). During the measurements, the working electrode potential was first increased in steps from the open circuit voltage (OCV, $\sim 0.75 \mathrm{~V}$ vs. RHE) to $-0.2 \mathrm{~V}$ vs. RHE, and then decreased back to OCV. The XAS spectra were recorded under each potential for at least $1 \mathrm{~h}$. Figure $4 \mathrm{a}, \mathrm{b}$ show in situ and operando Co K-edge XANES spectra of $n p-\mathrm{Co}_{0.85} \mathrm{Se}$ and $\mathrm{Pt} / \mathrm{np}-\mathrm{Co}_{0.85} \mathrm{Se}$, respectively. In Fig. $4 \mathrm{a}$, with increase of the operated bias voltages from the OCV to $-0.2 \mathrm{~V}$ vs. RHE, the absorption onset of $\mathrm{np}-\mathrm{Co}_{0.85} \mathrm{Se}$ shows no distinct change. While that of the $\mathrm{Pt} / \mathrm{np}-\mathrm{Co}_{0.85} \mathrm{Se}$ (Fig. $4 \mathrm{~b}$ ) shows the slight shift toward the higher energy, which is more obviously indicated by the firstorder derivatives of the XANES spectra as shown in Fig. 4c, d. The different behavior suggests the role of $\mathrm{Pt}$ and $\mathrm{Co}_{0.85} \mathrm{Se}$ electronic interactions on facilitating electron transfer from Co to Se atoms during HER. Moreover, similar behaviors of the Co-Se shell radial distance are also observed from the FT-EXAFS spectra shown in Fig. 4e, f. The shrinking of the radial distance of the CoSe shell with the applied bias is observed on $\mathrm{Pt} / \mathrm{np}-\mathrm{Co}_{0.85} \mathrm{Se}$ (Fig. 4f), while not on np- $\mathrm{Co}_{0.85} \mathrm{Se}$ (Fig. 4e), which further suggests the increase of electron intensities on $\mathrm{Pt} / \mathrm{Co}_{0.85} \mathrm{Se}^{20}$. Since water as a typical polar molecule consist of two $\mathrm{H}$ atoms carrying positive charge and an oxygen atom carrying negative charge, its oxygen atom could be easily captured by positively charged $\mathrm{Co}$ atom in $\mathrm{Pt} / \mathrm{np}-\mathrm{Co}_{0.85} \mathrm{Se}$, thus completing the adsorption and activation of water molecule. Moreover, the enhanced intensity of $\mathrm{Co}-\mathrm{OH}$ shell during HER for $\mathrm{Pt} / \mathrm{np}-\mathrm{Co}_{0.85} \mathrm{Se}$ indicates the more $\mathrm{OH}_{\text {ads }}$ adsorbed on Co atoms in Volmer reaction of HER process compared to that of $\mathrm{Co}_{0.85} \mathrm{Se}^{52}$. The above results indicate that $\mathrm{Pt}$ dopant might optimize the electronic structure of the surrounding $\mathrm{Co}$ atoms during $\mathrm{HER}$, which further accelerates the $\mathrm{H}_{2} \mathrm{O}$ adsorption and dissociation processes. According to the in situ and operando XAS results of $\mathrm{Pt} / \mathrm{np}-\mathrm{Co}_{0.85} \mathrm{Se}$ during $\mathrm{HER}, \mathrm{H}_{2} \mathrm{O}$ molecules are selectively adsorbed or bound on the Co sites at the early stages of the HER potential region (Step I depicted in Fig. 4g). Then, the $\mathrm{H}_{2} \mathrm{O}$ molecules in neutral media adsorb electrons that can be dissociated into intermediate $\mathrm{H}_{\mathrm{ads}}$ and 
a
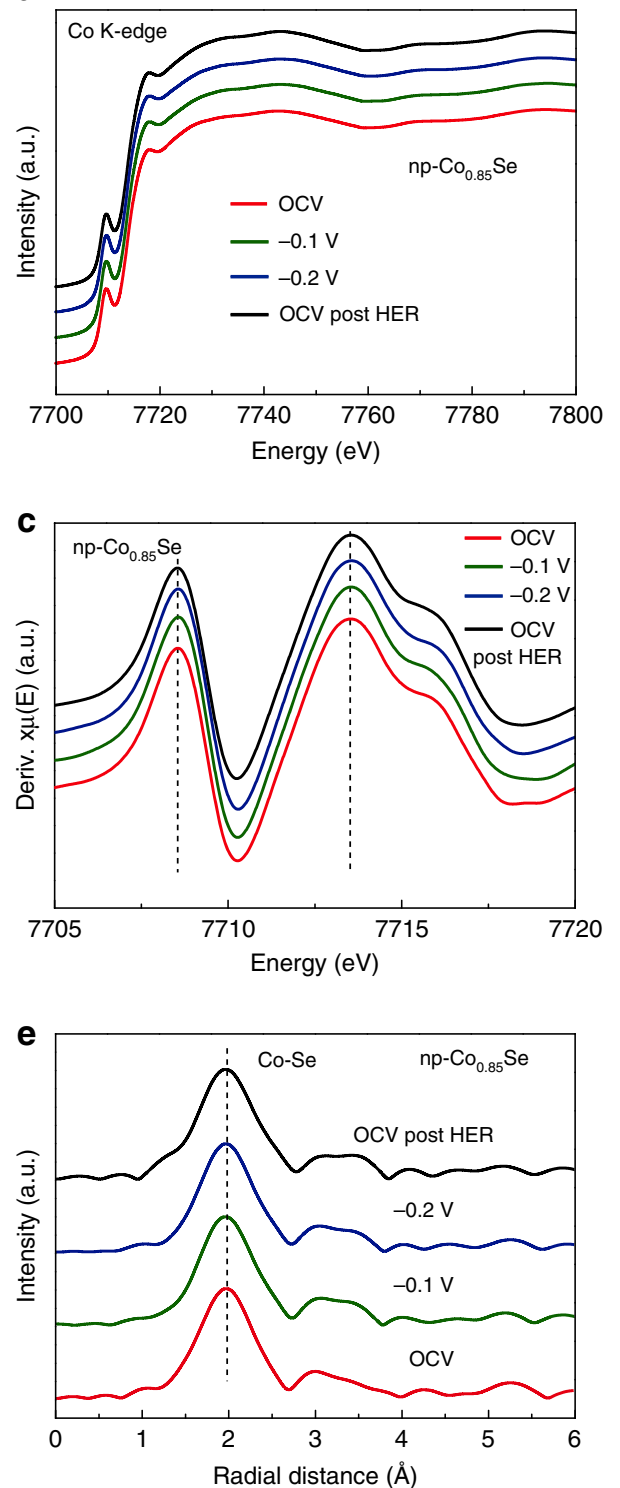

b

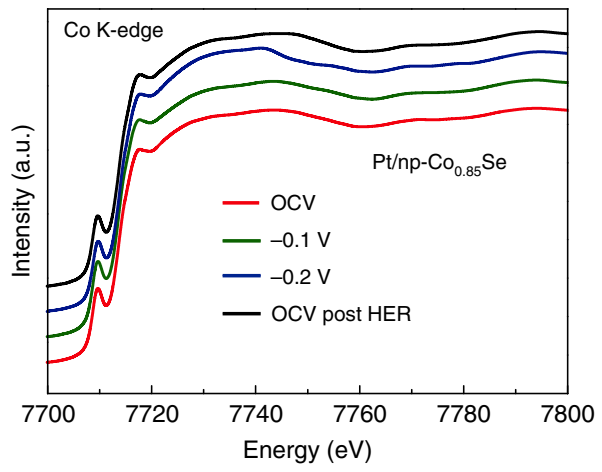

d

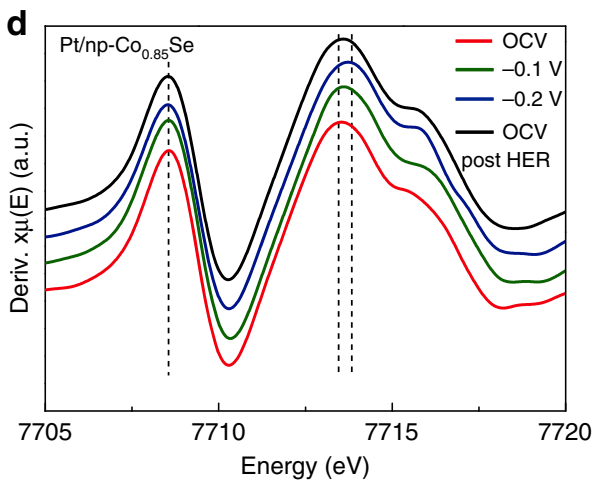

f

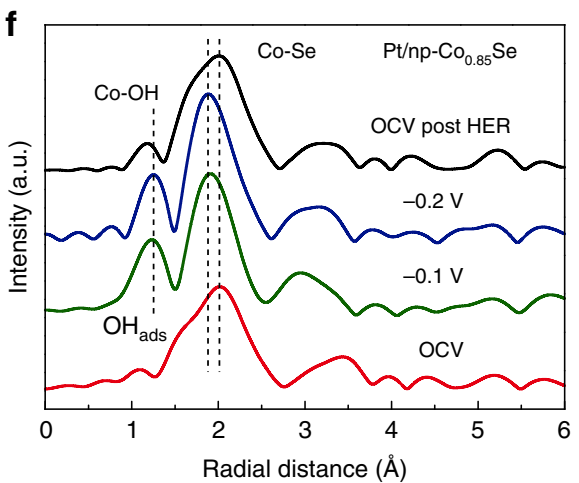

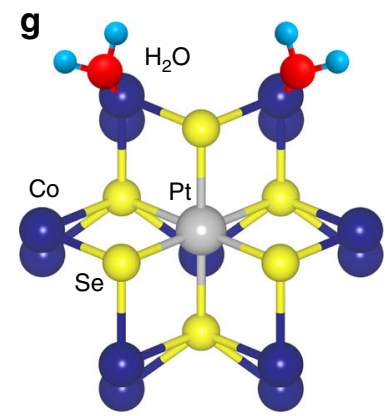

Dissociation $\lfloor$ Step I: Volmer

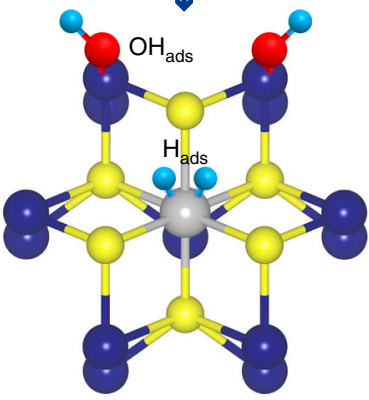

Desorption $\lfloor$ Step II : Tafel

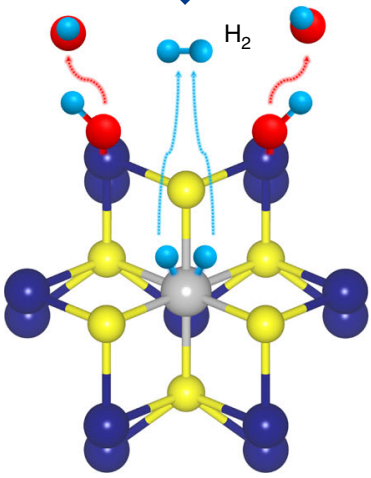

Fig. 4 In situ and operando X-ray absorption spectroscopy (XAS) characterizations. a, b Co K-edge XANES of a np- $\mathrm{Co}_{0.85} \mathrm{Se}_{\mathrm{and}} \mathbf{b} \mathrm{Pt} / \mathrm{np}-\mathrm{Co}_{0.85} \mathrm{Se}$ from

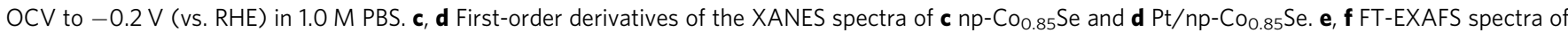
e $\mathrm{np}-\mathrm{CO}_{0.85} \mathrm{Se}$ and $\mathbf{f} \mathrm{Pt} / \mathrm{np}-\mathrm{CO}_{0.85} \mathrm{Se}$. $\mathbf{g}$ Schematic illustration of the hydrogen evolution reaction (HER) mechanism determined by in situ and operando XAS analysis of $\mathrm{Pt} / \mathrm{np}-\mathrm{Co}_{0.85} \mathrm{Se}$ in neutral media

$\mathrm{OH}_{\text {ads }}$ by Co sites through the Volmer step. Simultaneously, the generated $\mathrm{H}_{\text {ads }}$ could be adsorbed on a nearby empty Co site or $\mathrm{Pt}$ site and further be converted into $\mathrm{H}_{2}$ readily through the Tafel step (Step II shown in Fig. 4g).

Density functional theory (DFT) calculations were further constructed to examine how the individual components of $\mathrm{Pt} /$ $\mathrm{Co}_{0.85} \mathrm{Se}$ cooperate synergistically to enhance the neutral HER activity (Supplementary Note 5 and Figs. 20-22). The charge density difference images (Fig. 5a) reveal a strong charge redistribution at Pt-bonding region (red arrows) after the presence of single-atom $\mathrm{Pt}$ in $\mathrm{Pt} / \mathrm{Co}_{0.85} \mathrm{Se}$, which promotes a significant increase in the internal electron concentration of the system, thus enhancing the HER performance. Moreover, the projected density of states (PDOS) results reveal that the $\mathrm{Pt}$ dopant gives rise to some new hybridized electronic states in $\mathrm{Pt} /$ $\mathrm{Co}_{0.85} \mathrm{Se}$ (Fig. $5 \mathrm{~b}$ ), which could be ascribed to the hybridization between $\mathrm{Pt}$ ( $5 \mathrm{~d}$ orbitals) and $\mathrm{Se}$ atoms. Specifically, the comparison between the PDOS of the $\mathrm{Co}_{0.85} \mathrm{Se}$ and $\mathrm{Pt} / \mathrm{Co}_{0.85} \mathrm{Se}$ reveals that the change near the Fermi level is mainly contributed by the Co $3 \mathrm{~d}$ orbitals. This indicates that the Pt dopant could effectively optimize the d-electron domination of Co atoms, thus leading to enhanced catalytic activity. This result is consistent with the aforementioned XAS results (Fig. 2f, g). The DFT calculations were also employed to understand the kinetic energy barriers of the HER process. As shown in Fig. $5 \mathrm{c}, \mathrm{Co}_{0.85} \mathrm{Se}$ has a very large water dissociation energy barrier $\left(\Delta G\left(\mathrm{H}_{2} \mathrm{O}\right)=0.891\right.$ $\mathrm{eV})$, indicating an extremely sluggish Volmer process. In contrast, the $\Delta G\left(\mathrm{H}_{2} \mathrm{O}\right)$ of the $\mathrm{Pt} / \mathrm{Co}_{0.85} \mathrm{Se}$ dramatically decrease to only $0.491 \mathrm{eV}$, even lower than that of $\mathrm{Pt}(111)(0.563 \mathrm{eV})$, suggesting that the sluggish Volmer process can be greatly accelerated after the introduction of atomic-level $\mathrm{Pt}$ dopant ${ }^{53}$. Additionally, the calculated hydrogen adsorption free energy $\left(\Delta G_{\mathrm{H}}\right)$ in Fig. $5 \mathrm{~d}$ shows a $\Delta G_{\mathrm{H}}$ value of $-0.083 \mathrm{eV}$ for $\mathrm{Pt} / \mathrm{Co}_{0.85} \mathrm{Se}$ at Co sites and a $\Delta G_{\mathrm{H}}$ value of $-0.079 \mathrm{eV}$ for $\mathrm{Pt} / \mathrm{Co}_{0.85} \mathrm{Se}$ at $\mathrm{Pt}$ sites, which are comparable to that of Pt (111) (Supplementary Fig. 22). These results indicate that the Co sites are the active site for HER on 

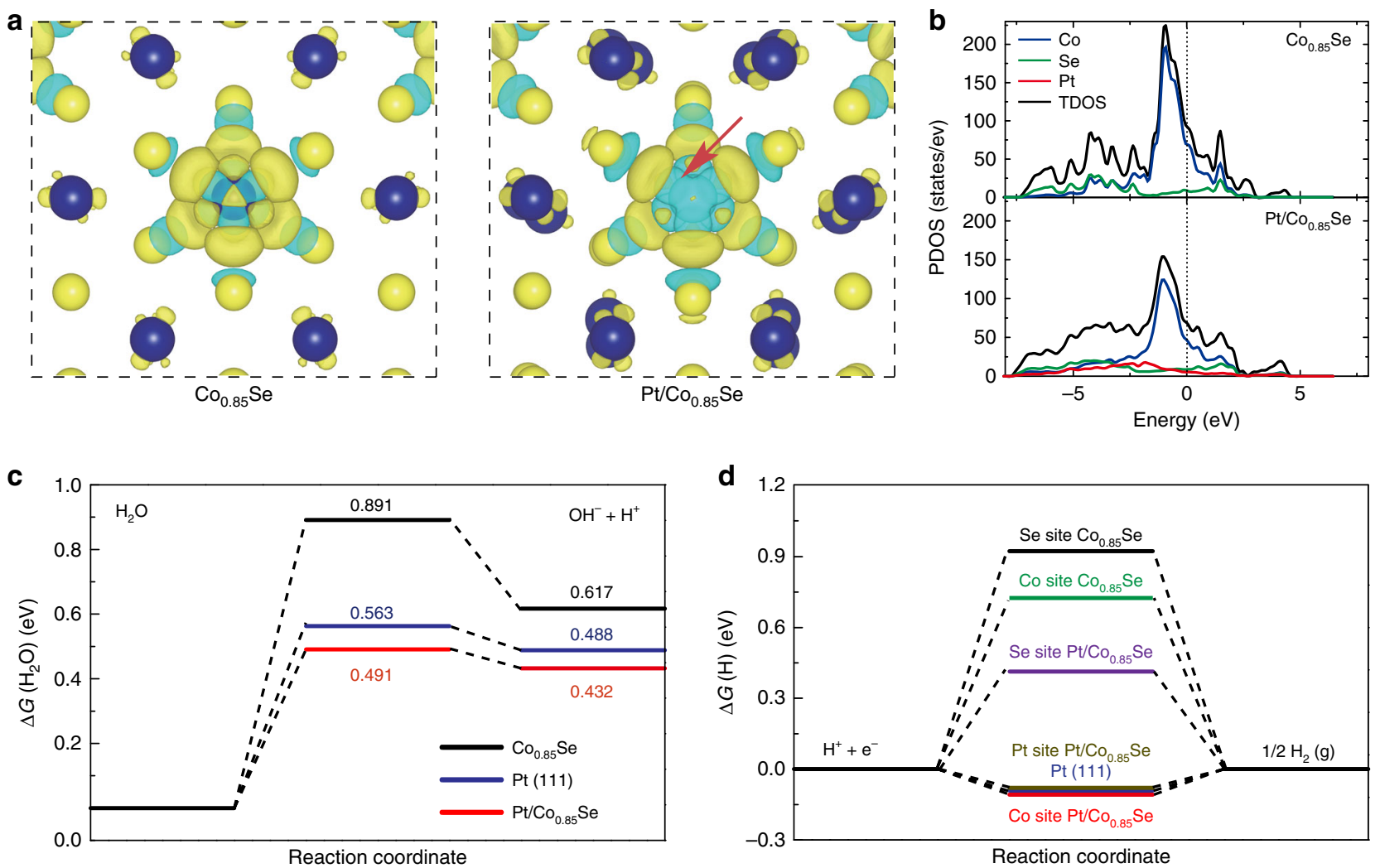

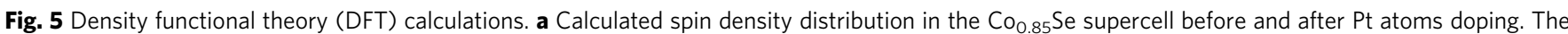
blue and yellow balls refer to $\mathrm{Co}$ and Se atoms. Yellow and cyan isosurfaces represent positive and negative spin densities $\left(0.005 \mathrm{e} / \AA^{3}\right)$, respectively. b Calculated DOS of $\mathrm{Co}_{0.85} \mathrm{Se}$ and $\mathrm{Pt} / \mathrm{Co}_{0.85} \mathrm{Se}$. c Calculated adsorption free energy diagrams for the Volmer step on the as-built np-Co $\mathrm{C}_{0.85} \mathrm{Se}, \mathrm{Pt}(111)$ and $\mathrm{Pt} / \mathrm{Co}_{0.85} \mathrm{Se}$ models. d Free energy diagrams for hydrogen adsorption at different active sites of $\mathrm{Co}_{0.85} \mathrm{Se}(004), \mathrm{Pt}(111)$, and $\mathrm{Pt} / \mathrm{Co} 0.85 \mathrm{Se}(004)$

$\mathrm{Pt} / \mathrm{Co}_{0.85} \mathrm{Se}$, and the proceeding of adsorption/desorption of $\mathrm{H}$ on $\mathrm{Pt} / \mathrm{Co}_{0.85} \mathrm{Se}$ is easier than on $\mathrm{Co}_{0.85} \mathrm{Se}$. Therefore, the introduction of $\mathrm{Pt}$ single-atom in $\mathrm{Pt} / \mathrm{np}-\mathrm{Co}_{0.85} \mathrm{Se}$ not only optimizes surface states of $\mathrm{Co}_{0.85} \mathrm{Se}$ active centers and reduces energy barriers of dissociated water molecules, but also significantly improves adsorption/desorption behavior of $\mathrm{H}$, which synergistically promote the HER thermodynamics and kinetics ${ }^{10}$.

\section{Discussion}

In summary, we have demonstrated that atomic engineering of $\mathrm{np}-\mathrm{Co}_{0.85} \mathrm{Se}$ by single $\mathrm{Pt}$ atoms doping is an effective approach to produce highly active and robust electrocatalysts for hydrogen evolution in aqueous media. The achieved $\mathrm{Pt} / \mathrm{np}-\mathrm{Co}_{0.85} \mathrm{Se}$ shows high HER activity with a near-zero onset overpotential, a low Tafel slope of $35 \mathrm{mV} \mathrm{dec}-1$, a high TOF of $3.93 \mathrm{~s}^{-1}$ at $-100 \mathrm{mV}$ vs. RHE, and a mass activity about 11 times greater than the commercial $\mathrm{Pt} / \mathrm{C}$ catalyst in neutral media. Besides, we reveal that the inert Co atoms are triggered by single-atom $\mathrm{Pt}$, thus turning into more active sites for water dissociation under catalytic conditions, by in situ and operando XAS measurements. DFT calculations further demonstrated that the electronic interactions between atomic-level $\mathrm{Pt}$ and $\mathrm{np}-\mathrm{Co}_{0.85} \mathrm{Se}$ can reduce energy barriers of dissociated water molecules, while significantly improve the adsorption/desorption behavior of $\mathrm{H}$ on $\mathrm{Pt} / \mathrm{np}$ $\mathrm{Co}_{0.85} \mathrm{Se}$ catalyst, which synergistically promote HER performance. This work not only provides a strategy to optimize local electronic structures of electrocatalysts for efficient hydrogen production, but also paves avenues to the further exploration and design of highly efficient electrocatalysts for other energy conversion applications.

\section{Methods}

Fabrication of $\mathbf{n p}-\mathrm{Co}_{\mathbf{0 . 8 5}} \mathbf{S e}$. The pure Co and CoSe powder were arc melt under an argon atmosphere to prepare Co-Se (85:15 at\%) alloy ingot. Then, the alloy ingot was re-melted and rapidly quenched by the rapidly rotating copper roller to obtain thin ribbons with homogeneous nanocrystalline two-phase structure. Finally, the ribbons were selectively etched at an etching voltage of $0.0 \mathrm{~V}$ vs. $\mathrm{Ag} /$ $\mathrm{AgCl}$ in $0.5 \mathrm{M} \mathrm{H}_{2} \mathrm{SO}_{4}$ solution by using an electrochemical workstation (Ivium CompactStat. h). The np- $\mathrm{Co}_{0.85} \mathrm{Se}$ ribbons were obtained after the full etching of the Co phase (about $2000 \mathrm{~s}$ ).

Fabrication of $\mathbf{P t} / \mathbf{n p}-\mathrm{CO}_{0.85} \mathrm{Se}$. Pt/np- $\mathrm{Co}_{0.85} \mathrm{Se}$ was synthesized by a electrochemical vacancy manufacturing and atom embedding strategy, which was performed using electrochemical workstation (Ivium CompactStat. $\mathrm{h}$ ) and a conventional three-electrode cell containing $0.5 \mathrm{M} \mathrm{H}_{2} \mathrm{SO}_{4}(40 \mathrm{ml})$. A np- $\mathrm{Co}_{0.85} \mathrm{Se}$ ribbon, a Pt foil $(2 \mathrm{~cm} \times 1 \mathrm{~cm})$ and an $\mathrm{Ag} / \mathrm{AgCl}$ electrode were used as the work electrode, counter electrode and reference electrode, respectively. CV was performed on the work electrode with a scan rate of $50 \mathrm{mV} \mathrm{s}^{-1}$ between -0.2 and $-0.7 \mathrm{~V}$ vs. $\mathrm{Ag} / \mathrm{AgCl}$.

Characterization. XRD measurements were conducted using a Bruker D8 Advance X-ray diffraction with $\mathrm{Cu}$ Ka radiation $(\lambda=1.5418 \AA)$. The characterizations of morphology and elemental composition were carried out by SEM (Zeiss Sigma HD equipped with an Oxford EDS) and TEM (JEM-ARM 200F). STEM images and EDX mappings were obtained on a JEM-ARM 200F. XPS was performed on Thermo Scientific ESCALAB250Xi spectrometer equipped with an $\mathrm{Al}$ $\mathrm{Ka}$ monochromatic. The specific surface and pore diameters data were collected by using the Brunauer-Emmet-Teller (BET) and Barrett-Joyner-Halenda (BJH) methods (Micromeritics ASAP 2020), respectively. ICP-OES was performed on Agilent 730 .

X-ray absorption spectroscopy measurements. The ex-situ X-ray absorption spectroscopy was carried out at the beamline BL01C1 in the fluorescence mode using a Lytle detector at National Synchrotron Radiation Research Center (NSRRC, Taiwan). The in-situ and operando XAS data were obtained on beamline BL01C1 at NSRRC in the fluorescence mode using a Lytle detector with a step-size of 0.25 $\mathrm{eV}$ at room temperature. Before the operando XAS measurements, an 
electrochemical workstation (Ivium CompactStat. h) and a custom-made poly tetra fluoroethylene (PTFE) cell were used. The catalysts were coated on the carbon cloth via drop casting to form a working electrode. Then, the PTFE cell containing $1.0 \mathrm{M}$ $\mathrm{PBS}$ was equipped with a $\mathrm{Pt} / \mathrm{np}-\mathrm{Co}_{0.85} \mathrm{Se}$ working electrode, a carbon rod counter electrode, and a saturated calomel reference electrode. The fresh electrolyte was bubbled with pure argon for $1 \mathrm{~h}$. Finally, the window of the PTFE cells was mounted at an angle of roughly $45^{\circ}$ with respect to both the incident beam and the detectors. During the operando experiments, the different potentials of OCV, -0.1 , and $-0.2 \mathrm{~V}$ vs. RHE were applied to the system. The as-obtained XAS data were processed with the ATHENA program.

Electrochemical measurements. All electrochemical measurements were performed on an electrochemical workstation (Ivium CompactStat. h) using a threeelectrode cell equipped with a graphite sheet as counter electrode and an $\mathrm{Ag} / \mathrm{AgCl}$ electrode (calibrated) as reference electrode. HER measurements were conducted in $0.5 \mathrm{M} \mathrm{H}_{2} \mathrm{SO}_{4}, 1.0 \mathrm{M} \mathrm{KOH}, 1.0 \mathrm{M} \mathrm{PBS}(\mathrm{pH}=7.0)$, respectively. Before test, all the fresh electrolytes were de-aerated with argon at room temperature. The sweep rate was set to $2 \mathrm{mV} \mathrm{s}^{-1}$ for $\mathrm{CV}$ measurements. The reference electrode was converted to RHE according to the Nernst equation $\left(E_{\mathrm{RHE}}=E_{\mathrm{Ag} / \mathrm{AgCl}}+0.0591 \mathrm{pH}+E_{\mathrm{Ag} / \mathrm{AgCl}}^{0}\right)$. EIS spectra were performed with a frequency ranging from $10^{6} \mathrm{~Hz}$ to $0.01 \mathrm{~Hz}$ and an amplitude of the sinusoidal voltage of $10 \mathrm{mV}$. The accelerated stability of electrodes was assessed by potential cycling between -0.4 and $-0.0 \mathrm{~V}$ vs. RHE with a sweep rate of $100 \mathrm{mV} \mathrm{s}^{-1}$. The current density-time curves were obtained at a static overpotential. To estimate the electrochemical capacitance, $\mathrm{CV}$ was carried out at different sweep rates. All CV curves were corrected for $i R$ losses unless noted. The calculation of current density is based on geometric area. To prepare the $\mathrm{Pt} / \mathrm{C}$ electrodes, $5.0 \mathrm{mg} \mathrm{Pt} / \mathrm{C}$ powder $\left(10 \mathrm{wt} \%\right.$ ), $1 \mathrm{ml}$ of isopropanol $/ \mathrm{H}_{2} \mathrm{O}$ (volume ratio, $1: 3)$ mixture and $15 \mu \mathrm{l}$ Nafion solution (5 wt\%) was mixed and then ultrasonicated for about $30 \mathrm{~min}$ to form a homogeneous ink. After that, a certain volume of dispersion was dropped onto the glassy carbon electrode and then dried at room temperature. The average loading catalyst was $\sim 2.04 \mathrm{mg} \mathrm{cm}^{-2}$.

Faradaic efficiency measurements. Faradaic efficiency of $\mathrm{Pt} / \mathrm{np}-\mathrm{Co}_{0.85} \mathrm{Se}$ was measured at different applied potentials $(-0.01,-0.05,-0.10,-0.15,-0.20$, $-0.25 \mathrm{~V}$ vs. RHE) by Gas chromatography (GC-2014C, Shimadzu) equipped with a thermal conductivity detector for $\mathrm{H}_{2}$ quantification. In a custom-made two compartment cell separated by a Nafion 117 membrane, each compartment of the cell was filled with $35 \mathrm{ml} 1.0 \mathrm{M}$ PBS solution. Ultra pure argon (Ar, 99.999\%) was used as the carrier gas.

\section{Data availability}

The data that support the plots within this paper and other findings of this study are available from the corresponding author upon reasonable request.

Received: 15 January 2019 Accepted: 25 March 2019

Published online: 15 April 2019

\section{References}

1. Chu, S. \& Majumdar, A. Opportunities and challenges for a sustainable energy future. Nature 488, 294-303 (2012).

2. Zou, X. \& Zhang, Y. Noble metal-free hydrogen evolution catalysts for water splitting. Chem. Soc. Rev. 44, 5148-5180 (2015).

3. Zhao, Z. et al. Surface-engineered PtNi-O nanostructure with record-high performance for electrocatalytic hydrogen evolution reaction. J. Am. Chem. Soc. 140, 9046-9050 (2018).

4. Subbaraman, R. et al. Enhancing hydrogen evolution activity in water splitting by tailoring $\mathrm{Li}^{+}-\mathrm{Ni}(\mathrm{OH})_{2}-\mathrm{Pt}$ interfaces. Science 334, 1256-1260 (2011).

5. Yin, $\mathrm{H}$. et al. Ultrathin platinum nanowires grown on single-layered nickel hydroxide with high hydrogen evolution activity. Nat. Commun. 6, 6430 (2015).

6. Yan, H. et al. Phosphorus-modified tungsten nitride/reduced graphene oxide as a high-performance, non-noble-metal electrocatalyst for the hydrogen evolution reaction. Angew. Chem. Int. Ed. 54, 6325-6329 (2015).

7. Caban-Acevedo, M. et al. Efficient hydrogen evolution catalysis using ternary pyrite-type cobalt phosphosulphide. Nat. Mater. 14, 1245-1251 (2015).

8. Staszak-Jirkovsky, J. et al. Design of active and stable Co-Mo-Sx chalcogels as $\mathrm{pH}-$ universal catalysts for the hydrogen evolution reaction. Nat. Mater. 15, 197-203 (2016).

9. Wang, P. et al. Precise tuning in platinum-nickel/nickel sulfide interface nanowires for synergistic hydrogen evolution catalysis. Nat. Commun. 8, 14580 (2017).

10. Zheng, Y. R. et al. Doping-induced structural phase transition in cobalt diselenide enables enhanced hydrogen evolution catalysis. Nat. Commun. 9, 2533 (2018).

11. Luo, Z. et al. Chemically activating $\mathrm{MoS}_{2}$ via spontaneous atomic palladium interfacial doping towards efficient hydrogen evolution. Nat. Commun. 9 , 2120 (2018).
12. Liu, B. et al. Nickel-cobalt diselenide 3D mesoporous nanosheet networks supported on ni foam: An all-pH highly efficient integrated electrocatalyst for hydrogen evolution. Adv. Mater. 29, 1606521 (2017).

13. Kong, D. et al. First-row transition metal dichalcogenide catalysts for hydrogen evolution reaction. Energy Environ. Sci. 6, 3553 (2013).

14. Deng, J. et al. Triggering the electrocatalytic hydrogen evolution activity of the inert two-dimensional $\mathrm{MoS}_{2}$ surface via single-atom metal doping. Energy Environ. Sci. 8, 1594-1601 (2015).

15. Hou, Y. et al. Vertically oriented cobalt selenide/NiFe layered-doublehydroxide nanosheets supported on exfoliated graphene foil: an efficient 3D electrode for overall water splitting. Energy Environ. Sci. 9, 478-483 (2016).

16. Zhao, Y. et al. Charge state manipulation of cobalt selenide catalyst for overall seawater electrolysis. Adv. Energy Mater. 8, 1801926 (2018).

17. Popczun, E. J. et al. Nanostructured nickel phosphide as an electrocatalyst for the hydrogen evolution reaction. J. Am. Chem. Soc. 135, 9267-9270 (2013).

18. Tan, Y. et al. Versatile nanoporous bimetallic phosphides towards electrochemical water splitting. Energy Environ. Sci. 9, 2257-2261 (2016).

19. Tian, J. et al. Self-supported nanoporous cobalt phosphide nanowire arrays: an efficient 3D hydrogen-evolving cathode over the wide range of $\mathrm{pH} 0-14$. J. Am. Chem. Soc. 136, 7587-7590 (2014).

20. Saadi, F. H. et al. Operando spectroscopic analysis of CoP films electrocatalyzing the hydrogen-evolution reaction. J. Am. Chem. Soc. 139, 12927-12930 (2017).

21. Zhang, $\mathrm{R}$. et al. Ternary $\mathrm{NiCo}_{2} \mathrm{Px}$ nanowires as $\mathrm{pH}$-universal electrocatalysts for highly efficient hydrogen evolution reaction. Adv. Mater. 29, 1605502 (2017).

22. Xue, Z. H. et al. Janus $\mathrm{Co} / \mathrm{CoP}$ nanoparticles as efficient Mott-Schottky electrocatalysts for overall water splitting in wide $\mathrm{pH}$ range. Adv. Energy Mater. 7, 1602355 (2017).

23. Popczun, E. J. et al. Highly active electrocatalysis of the hydrogen evolution reaction by cobalt phosphide nanoparticles. Angew. Chem. Int. Ed. 53, 5427-5430 (2014).

24. Wang, $\mathrm{H}$. et al. $\mathrm{Co}_{0.85} \mathrm{Se}$ hollow nanospheres anchored on $\mathrm{N}$-doped graphene nanosheets as highly efficient, nonprecious electrocatalyst for hydrogen evolution reaction in both acid and alkaline media. J. Power Sources 400, 232-241 (2018).

25. Meng, T. et al. In situ coupling of $\mathrm{Co}_{0.85} \mathrm{Se}$ and $\mathrm{N}$-doped carbon via one-step selenization of metal-organic frameworks as a trifunctional catalyst for overall water splitting and $\mathrm{Zn}$-air batteries. J. Mater. Chem. A 5, 7001-7014 (2017).

26. Yu, B. et al. Nanocrystalline $\mathrm{Co}_{0.85} \mathrm{Se}$ as a highly efficient non-noble-metal electrocatalyst for hydrogen evolution reaction. Electrochim. Acta 247, 468-474 (2017).

27. $\mathrm{Yu}, \mathrm{B}$. et al. Nanocrystalline $\mathrm{Co}_{0.85} \mathrm{Se}$ anchored on graphene nanosheets as a highly efficient and stable electrocatalyst for hydrogen evolution reaction. ACS Appl. Mater. Inter. 9, 30703-30710 (2017).

28. Cheng, N. et al. Platinum single-atom and cluster catalysis of the hydrogen evolution reaction. Nat. Commun. 7, 13638 (2016).

29. Tiwari, J. N. et al. Multicomponent electrocatalyst with ultralow Pt loading and high hydrogen evolution activity. Nat. Energy 3, 773-782 (2018).

30. Mao, J. et al. Accelerating water dissociation kinetics by isolating cobalt atoms into ruthenium lattice. Nat. Commun. 9, 4958 (2018).

31. Cheng, X. et al. Highly active, stable oxidized platinum clusters as electrocatalysts for the hydrogen evolution reaction. Energy Environ. Sci. 10, 2450-2458 (2017).

32. Zhang, L. et al. Potential-cycling synthesis of single platinum atoms for efficient hydrogen evolution in neutral media. Angew. Chem. Int. Ed. 56, 13694-13698 (2017).

33. Tavakkoli, M. et al. Electrochemical activation of single-walled carbon nanotubes with pseudo-atomic-scale platinum for the hydrogen evolution reaction. ACS Catal. 7, 3121-3130 (2017).

34. Qiu, H. J. et al. Nanoporous graphene with single-atom nickel dopants: an efficient and stable catalyst for electrochemical hydrogen production. Angew. Chem. Int. Ed. 54, 14031-14035 (2015).

35. Zhang, J. et al. Single platinum atoms immobilized on an MXene as an efficient catalyst for the hydrogen evolution reaction. Nat. Catal. 1, 985-992 (2018).

36. Liu, L. \& Corma, A. Metal catalysts for heterogeneous catalysis: from single atoms to nanoclusters and nanoparticles. Chem. Rev. 118, 4981-5079 (2018).

37. Tan, Y. et al. 3D nanoporous metal phosphides toward high-efficiency electrochemical hydrogen production. Adv. Mater. 28, 2951-2955 (2016).

38. Chen, R. et al. Use of platinum as the counter electrode to study the activity of nonprecious metal catalysts for the hydrogen evolution reaction. ACS Energy Lett. 2, 1070-1075 (2017).

39. Topalov, A. A. et al. Towards a comprehensive understanding of platinum dissolution in acidic media. Chem. Sci. 5, 631-638 (2014).

40. Tavakkoli, M. et al. Functionalized carbon nanotubes with Ni(II) bipyridine complexes as efficient catalysts for the alkaline oxygen evolution reaction. ACS Catal. 7, 8033-8041 (2017).

41. Lin, L. et al. Low-temperature hydrogen production from water and methanol using Pt/alpha-MoC catalysts. Nature 544, 80-83 (2017). 
42. Chen, Y. et al. Discovering partially charged single-atom Pt for enhanced antiMarkovnikov alkene hydrosilylation. J. Am. Chem. Soc. 140, 7407-7410 (2018).

43. Zhang, J. et al. Cation vacancy stabilization of single-atomic-site $\mathrm{Pt}_{1} / \mathrm{Ni}(\mathrm{OH}) \mathrm{x}$ catalyst for diboration of alkynes and alkenes. Nat. Commun. 9, 1002 (2018).

44. Zhang, H. et al. Integrated hierarchical carbon flake arrays with hollow Pdoped $\mathrm{CoSe}_{2}$ nanoclusters as an advanced bifunctional catalyst for $\mathrm{Zn}$-Air batteries. Adv. Funct. Mater. 28, 1804846 (2018).

45. Chen, W. et al. Neighboring Pt atom sites in an ultrathin FePt Nanosheet for the efficient and highly CO-tolerant oxygen reduction reaction. Nano Lett. 18, 5905-5912 (2018).

46. Xing, Z. et al. Ultrafine Pt nanoparticle-decorated $\mathrm{Co}(\mathrm{OH})_{2}$ nanosheet arrays with enhanced catalytic activity toward hydrogen evolution. ACS Catal. 7, 7131-7135 (2017).

47. Liu, B. et al. Cobalt-nanocrystal-assembled hollow nanoparticles for electrocatalytic hydrogen generation from neutral-pH water. Angew. Chem. Int. Ed. 55, 6725-6729 (2016).

48. Fei, H. et al. Atomic cobalt on nitrogen-doped graphene for hydrogen generation. Nat. Commun. 6, 8668 (2015).

49. Liang, H. W. et al. Molecular metal-Nx centres in porous carbon for electrocatalytic hydrogen evolution. Nat. Commun. 6, 7992 (2015).

50. Li, K. et al. Enhanced electrocatalytic performance for the hydrogen evolution reaction through surface enrichment of platinum nanoclusters alloying with ruthenium in situ embedded in carbon. Energy Environ. Sci. 11, 1232-1239 (2018).

51. Xue, Y. et al. Anchoring zero valence single atoms of nickel and iron on graphdiyne for hydrogen evolution. Nat. Commun. 9, 1460 (2018).

52. Jia, Q. et al. Experimental observation of redox-induced Fe-N switching behavior as a determinant role for oxygen reduction activity. ACS Nano $\mathbf{9}$, 12496-12505 (2015).

53. Chen, G. et al. Accelerated hydrogen evolution kinetics on NiFe-layered double hydroxide electrocatalysts by tailoring water dissociation active sites. Adv. Mater. 30, 1706279 (2018).

\section{Acknowledgements}

We gratefully acknowledge financial supported by the National Natural Science Foundation of China (Grant No. 51771072), the Youth 1000 Talent Program of China, the Fundamental Research Funds for the Central Universities, and Hunan University State Key Laboratory of Advanced Design and Manufacturing for Vehicle Body Independent Research Project (No. 71860007).

\section{Author contributions}

Y.W.T. conceived and supervised this study. K.J. and Y.Z. carried out materials fabrication, XRD/SEM/XPS characterization, and electrochemical measurements. S.C.N. conducted the TEM characterization. M.L. performed the density functional calculations and computational models. B.L., P.M., Y.R.L., T.S.C., F.M.F. de G. contributed to the XAS measurements and analysis of the XAS experiments results. Y.W.T. and K.J. wrote the paper. All authors contributed to discussions and manuscript review.

\section{Additional information}

Supplementary Information accompanies this paper at https://doi.org/10.1038/s41467019-09765-y.

Competing interests: The authors declare no competing interests.

Reprints and permission information is available online at http://npg.nature.com/ reprintsandpermissions/

Journal peer review information: Nature Communications thanks the anonymous reviewers for their contribution to the peer review of this work. Peer reviewer reports are available.

Publisher's note: Springer Nature remains neutral with regard to jurisdictional claims in published maps and institutional affiliations.

(c) (i) Open Access This article is licensed under a Creative Commons Attribution 4.0 International License, which permits use, sharing, adaptation, distribution and reproduction in any medium or format, as long as you give appropriate credit to the original author(s) and the source, provide a link to the Creative Commons license, and indicate if changes were made. The images or other third party material in this article are included in the article's Creative Commons license, unless indicated otherwise in a credit line to the material. If material is not included in the article's Creative Commons license and your intended use is not permitted by statutory regulation or exceeds the permitted use, you will need to obtain permission directly from the copyright holder. To view a copy of this license, visit http://creativecommons.org/ licenses/by/4.0/.

(c) The Author(s) 2019 